\title{
The Cultural Interpretation and Digitalization of Zhuxian Town Woodblock New Year Painting
}

\author{
Hui Li \\ School of Art Design \\ Huanghe Science and Technology College \\ Zhengzhou, China \\ e-mail: 46119080@qq.com
}

\begin{abstract}
Combining the development of digital art design as a new cultural industry and the needs of the market, this paper tends to conduct the case study of Zhuxian Town Woodblock New Year Painting of Henan province. It aims to analyze the art elements, cultural genes and human environment for the formation of traditional aesthetical style of Zhuxian town woodblock New Year painting and strives to get the overall grasp of its actual basic situation and characteristics. For the purposes of protection, development and utilization, taking about how Zhuxian Town Woodblock New Year Painting and digital art language are used in practice as an example, this paper discusses how it better meets the needs of modern economy and society as a traditional cultural industry so as to produce greater social, cultural and economic value.
\end{abstract}

Keywords-Zhuxian Town Woodblock New Year Painting; digital art; Central Plains traditional culture

\section{INTRODUCTION}

As the society has entered the new stage of digital art, the new media art which developed in the 60s of twentieth Century and gradually flourishes nowadays, provides a new platform for the all-around creation by artists, leading a new round of art trend. While as the representative of Central Plains folk culture industry, Zhuxian Town Woodblock New Year Painting of Henan province has got stuck in its development. Zhuxian Town Woodblock New Year Painting has a long history and is the founder of the woodblock New Year paintings. Yangliuqing New Year Paintings of Tianjin, Taohuawu New Year Paintings of Jiangsu and New Year paintings of Weifang, Shandong have been influenced by it to varying degrees. However, the traditional immutable content and form of it could not fully get adapted to the contemporary society as the time changes, which is the common problem that the traditional cultural industry encounters in the background of globalization.

Actually some economically developed countries and regions do not abandon traditional culture industry while welcoming modern civilization. On the contrary, various traditional culture industries not only fully get adapted to the modern society, but also spurt very strong vitality, creating very high social, cultural and economic value. For example, the Japanese ukiyoe and French wine culture etc. In the times of the fast development of Central Plain, only by deeply excavating the artistic value and cultural connotation of the
Zhuxian Town Woodblock New Year Painting, expanding the content and form of it in more channels, breaking through the bottleneck of the development can we create cultural arts of high quality, expand its spreading, further improve the popularity of Zhuxian Town Woodblock New Year painting and enhance the soft power of Central Plain culture.

\section{The REFLECTION OF TRADITIONAL CULTURE IN ZHUXIAN TOWN WOODBLOCK NEW YEAR PAINTING}

\section{A. The Creation Ideas of 'the Unity of Man and Nature'}

Chinese ancient philosophy is based on the "The Book of Changes" and the theory of Yin-Yang and five elements, which not only determines the way of thinking of Chinese folk culture, but also deeply influences ordinary people's view of life which emphasizes birth and life and their view of emotion. While as a type of Chinese auspicioous folk art, the Zhuxian Town Woodblock New Year Painting is greatly influenced by national philosophy. In Chinese traditional folk auspicious culture, the thoughts of "harmony between man and nature, the chaos of yin and Yang, symbolism and metaphor" are the most common ways of thinking and creation logic. In the theory of Yin-Yang and five elements, "the heaven", "the earth" and "human being" are interrelated as a unity. It is believed that everything in nature is created by heaven and earth in the process of the mutual conversion between yin and Yang. Therefore people believe that "the heaven", "the earth" and "human being" coexist in the unity and commonly follow the motion law of life, just as the ideas of "the correspondence between man and universe", "the harmony between man and nature" and "Human-Environmental Interrelation" emphasized in Meridians and Vessels in the chapter of On Cough in the book of Huangdi Neijing. "Zhuang-zi Dasheng" reads that the heaven and earth are parents of all things." "Book of changes" emphasizes the doctrine of three elements in which "the heaven", "the earth" and "human being" co-exist and human is put in the central position, showing his important status. The law of Heaven lies in that the heaven is the beginning of everything. The law of earth believes that the earth creates everything. The law of human lies in that human beings help the growth of everything. The law of Heaven values Yin and Yang. The law of earth focuses on weakness and strength. The law of human puts emphasis on righteousness. Although the three have their respective believes, they are corresponding to 
each other and interrelated. This is not only a kind of "identity and relationship", but also a kind of the internal generating relations and realization principles. The law of heaven and earth is the generation principle and the law of human is the realization principle, the two of which are indispensable, involving the meaning of close relationship between man and nature. As a Chinese traditional folk auspicious art, the creation idea of Zhuxian Town Woodblock New Year Painting fully displays such ideological connotation, such as being plump, reunion and integrity, even numbers, symmetry. The coexistence of yin and Yang and combination of being static and dynamic are the techniques of such characteristics.

In addition, the creation idea of Zhuxian Town Woodblock New Year Painting lies in that it integrates the subjective needs of drawing on the advantages and avoiding disadvantages, valuing birth and life, praying for happiness into the overall modeling of New Year paintings naturally and harmoniously, constructing pictures revealing the co-existence of the heaven, earth and human, achieving the ideal state of harmonious unity in them, which fully embodies the creation concept of "the harmony between man and nature".

\section{B. The Folk aesthetic interest influenced by Central Plains culture}

Among the five elements, the one in the center is the earth which corresponds to Central Plains. The Central Plains of the Yellow River basin area has entered the times of agricultural civilization thousands of years ago where the folk customs are simple and of profound history. Influenced by the Confucian culture, the Central Plains culture, on the one hand, is exclusive and conservative, emphasizing orthodox, maintaining a hierarchical order and government standard, while on the other hand, it is also inclusive and open because of its convenient location leading to all directions. Those factors thus form a fully inclusive and equitable, generous culture of Central Plains and also form the virtuous and conservative attitude of people there. Such attitude applied to folk aesthetic taste forms the rules that only pure and primitive color are used. Besides, the picture must be lively and festive, and patterns should be of auspicious meaning with explicit sources. It is in such human background that Zhuxian Town Woodblock New Year painting has formed its own unique artistic features of being simple, unsophisticated, heavy-colored and local".

\section{The Exploration of Aesthetic Mode in the Process of THE DigITALIZATION OF ZHUXIAN TOWN WOODBLOCK NEW YEAR PAINTING}

\section{A. Color Schemes}

The color expression in Zhuxian Town Woodblock New Year Painting contains Chinese ancient, unique color science and aesthetic system, which are living fossils with traditional and uninterrupted source of aesthetic factors. The basic colors are green, red, yellow, white and black which are consistent with the traditional "five colors". The underlying meanings of traditional "five colors" are the five elements of metal, wood, water, fire and soil which symbolize the continuation and exuberance of life and the prosperity of whole family. The application of "five colors” in Zhuxian Town Woodblock New
Year Painting has become subtle ways of praying for blessing and longevity. Both of its color and aesthetic aspects embody the essence of Chinese traditional culture. Because the color is extracted from the natural material, so the color is rich and harmonious which comes to the unity with ink lines. In the aspect of painting, the Zhuxian Town Woodblock New Year Painting uses ancient woodblock printing. Only one color is used for one printing without any more drawing or painting, paying attention to the overall effect. The painting of decorative folk New Year painting is in particular so. Its color is very representative, which is thick and strong, rich and bright, underlining auspicious and joyous, lively and romantic atmosphere. It's bold and exaggerated for the combination of colors. Despite the folk argument that yellow combined with purple is hideous, Zhuxian Town Woodblock New Year painting combines yellow with purple, the colors of which are heavy and strongly contrast with each other, achieving unexpected visual effect. Such way of using colors not only satisfies the human visual perception to the maximum degree, but also accords with the basic laws that the essential demands for coloring figure lie in supplementing primary colors, thus it's distinctive in style and has strong ornamental effect. In addition to strong contrasts and heavy colors, it also shows the pursuit of elegant and harmonious color effect. The color used on the head part shows ingenuity. Similar to the features of face printing in dramas, the eyelid is painted with orange red and forehead and face are painted with red and green. Besides, there must be proper blank, making it simple and lively, which is the specific method of color combination applied in Zhuxian Town Woodblock New Year painting. The colors used in Zhuxian Town Woodblock New Year Painting are pure and clear. The symbolic characteristics are suitable for the color settings of digital art and reflect the unique aesthetic tendency of the region and nation. Starting from the traditional folk art, combined with modern digitalized design, the digital art design develops a new style which makes it fresh and new.

\section{B. The Setting of Lines}

Zhuxian Town Woodblock New Year Painting takes lines as the main means of expression. Just as important as the requirement for the forcefulness of writing in Chinese calligraphy and painting, rough lines and strong color contrast achieve the visual balance skillfully, showing vigorous beauty with proper degree of forcefulness. In the creation and printing process of New Year paintings, the ink line version is the master of New Year paintings, which is commonly known as "black plate" among artists. In the modeling of Zhuxian Town Woodblock New Year Painting, lines work as frame and the plane is the content. Lines construct frame for planes. Therefore, the shape and density of lines are of great importance. So we have good reason to believe that lines play key roles in the composition of picture, which strengthens the decoration effects of the Zhuxian Town Woodblock New Year Painting. Therefore, the schemes of lines must comply with the aesthetic laws. Mr. Lu Xun set high value of it: "The Woodblock New Year Painting in Zhuxian Town is splendid, the lines of which are bold and strong, varying from that of other places." The digital art design can be combined with New Year Paintings Art, learning their planarity and symbolic characteristics, generalizing structure, combining the elements 
of points, lines and planes, which make the digital art concise in pattern, reflecting the elegant simplicity. It is also in line with the simplification required in digital art design.

\section{Character Modeling}

The design of figures in the Zhuxian Town Woodblock New Year Painting shows the pursuit of plane visual effect with proper degree of density. It's in general rich and full with strong adornment features. Mr. Lu Xun said: "Zhuxian Town Woodblock New Year Painting is simple and plain with strong colors. The characters wear neither powder nor obsequiousness. They are of local features, bearing unique characteristics of New Year paintings in North China." The modeling of Zhuxian Town Woodblock New Year Painting is image in nature. It involves the ideas of people and embodies a certain meaning and connotation. Such as the painting with a monkey sitting on the horse meaning getting an official status immediately and the painting in which there is a boy holding a lotus and fish meaning wealth in the coming years. The homophonic of Chinese cabbage is 'baicai' , meaning abundant wealth. The homophonic of bat is "Fu", meaning 'blessing' etc. These symbolic modeling involve profound connotation and fine message inherited by people, becoming a part of the folk arts modeling rich in aesthetic value. Combining these folk culture elements with digital art, using this technique of symbolizing in the design of modern digital art, with the help of computer software technology, transforming the abstract concept into a specific image, making pictures more vivid and convincing would undoubtedly create Chinese local digital art image with strong local feature.

\section{Modes of Composition}

In terms of the composition, the Zhuxian Town Woodblock New Year Painting makes the theme stand out and composite the picture with unique and bold design, focusing on spirit and connotation, major role and minor role, sparsity and density etc. The so-called spirit greatly displays the spirit of characters, emphasizing the resemblance in spirit rather than in form in the aspects of profiling, environment, clothing and props; Connotation means to apply the techniques of analogy, association, metaphor and indication to express meanings implicitly or explicitly. Such as chicken meaning 'blessing', lanterns implying promotion, lotus meaning successiveness and bat containing happiness"; The major role refers to idea that for the core part of pictures, from the fixing of position to gestures, careful scrutiny must be made so as to highlight the major role, making the vivid portrayals are all in it; the minor role is to determine the supporting role. The main character is usually put at the center of the picture and the supporting roles should be placed on top, at bottom, on left or right, especially when the beauty and ugliness, God and ghost, good and evil characters are painted in the same picture, the main characters must be painted in big size and the minor ones smaller in size. Sparsity and density refer to the arrangement of characters and props, facial features and clothing should be with proper degree of density. Especially in the picture with many characters in it, proper density and unity in diversity must be achieved.

Zhuxian Town Woodblock New Year Painting is balanced in composition, rich and full. They are highly decorative.
Straight lines and curves are used properly for the division of pictures. The segmentation of the picture combines vigor and suppleness, showing a strong sense of rhythm, revealing modern sense of plane composition and the oriental national characteristics. At present, Chinese digital art imitates foreign composition techniques, which mainly applies the squares form. It has obtained the certain effect of picture saturation and visual impact, but at the same time made the audience have a visual fatigue. The composition of Zhuxian Town New Year paintings is unique and fun, which works as an important aspect which the digital art can learn from.

\section{CUlTURAL INHERITANCE AND DESIGN INNOVATION IN THE DigITALIZATION OF ZHUXIAN TOWN WOODBLOCK NEW YEAR PAINTING}

\section{A. Exploring the Modern Value of Local Classical Subjects}

Zhuxian Town Woodblock New Year Painting is rich in type and abundant in content. It is drawn mainly from the historical drama, romance novels, fairy tales and folk legends, the theme and content of which come down in one continuous line with the traditional Chinese culture. The profound history of Zhuxian Town Woodblock New Year Painting provides internal support for the localization of digital art. With the long historical culture of Zhuxian Town Woodblock New Year Painting as the background to develop digital art industry can meet the needs of seeking characterized and localized development. Exploring folk art resources makes the digital art practitioners grasp the method of inheritance and the protection of cultural heritage in the process of collection, sorting, screening, and gradually finds their own cultural identity and sense of cultural belongings. Combining the Zhuxian Town Woodblock New Year Painting with digital art design is a winwin strategy: on the one hand, digital art has the most intuitive folk art elements and improves new vitality because of the integration of the Zhuxian Town woodcut New Year paintings in it; on the other hand, Zhuxian Town Woodblock New Year Painting continues to develop and prevent from the doom of extinction.

\section{B. Based on local culture, borrowing regional features in form}

Zhuxian Town Woodblock New Year Painting contains unique forms of artistic expression. It's full in composition, rough and concise in the use of lines, bright in colors, simple and exaggerated in the creation of characters. Such artistic characteristics provide the digital art with a lot of available resources. In the digitalization of the Zhuxian Town Woodcut New Year Painting, we should inherit its art form and excavate its cultural connotation. Besides, we could consider to make the cultural art involved in New Year paintings symbolized and multidimensional. We could extract its specific nature, retain its unconventional, asymmetry and simple characteristics, learn its bright colors and bold lines and bring them to the digital art design as the symbols of Central Plains folk culture. Try to achieve innovation on the base of the symbolization of Zhuxian Town Woodblock New Year Painting and develop it from twodimension to three-dimension, such as some images to popular taste are made into three-dimensional modeling as "Olympic 
Fuwa", and applied to the design of indoor ornaments, key chain, cushion and other products, which can not only expand industry chain of creative digital art, but also can make the Zhuxian Town Woodblock New Year Painting spread widely, reflecting the cultural and economic value at the same time.

\section{CONCLUSIONS}

As modern art is becoming increasingly globalized and diversified, digital art is becoming more and more localized, individualized and nationalized. Emphasizing the exploration of symbolic language and cultural connotation of folk art's modeling elements plays an important role in the inheritance of national spirit and culture in the digital age. Zhuxian Town Woodblock New Year Painting is an important symbol of the Central Plains culture. From the perspective of the integration of culture and technology, the in-depth study of the art language connotation and cultural significance of it and the development and exploration of its rich cultural artistic value in new form and content will be beneficial for its better adaptation to the modern economic society and produce greater economic value as well. This is also the responsibility of us entrusted by history.

\section{REFERENCES}

[1] Pan Lusheng, Tang Jialu. The Introduction to Folklore [M]. Shangdong Education Press, 2002.10

[2] Dang Zhichun. Zhongyuan Folk Crafts and Arts [M]. Henan People Press, 2006.4

[3] Zhou Yuexi. The Analysis of Colors of Zhuxian Town Woodcut New Year Paintings---the Discussion with Mr.Zhou Donghai [J]. Arts Theory and Criticism, 2006.6

[4] Shenchang, Shen Shaochun. Henan Art History [M]. Chinese Ancient Books Press, 2002. 
